\title{
Some psychological factors in Parkinsonism
}

\author{
SANDRA HORN
}

From the Wessex Neurological Centre, Southampton

SUMMARY Twenty-four Parkinsonism patients were compared with 'normal controls' and with another chronically disabled group, matched for age, sex distribution, and socioeconomic background, on measures of depression and some intellectual factors. A tendency to depression in the Parkinsonism sufferers was demonstrated together with an apparent specific intellectual deficit, for which a cause related to the motor disabilities of the disease is postulated.

When, in 1817 James Parkinson wrote his monograph describing 'the shaking palsy', he considered that the disease process left the senses and intellect uninjured. This opinion has, since then, been questioned repeatedly. Lewy (1923) was of the opinion that mental disturbances are so common in Parkinsonism that they must be considered part of the disease. He examined 70 cases psychiatrically and found that of these only 16 could be described as mentally healthy, and that the majority of the others had disturbances of the true dementia type. It should be stressed, as he himself pointed out, that he was referring only to advanced cases such as are found in hospitals. Mjönes (1949) noted in an extensive review that, of the mental symptoms occurring during the course of the disease, there was a relatively higher incidence of the organic type. More recently, Hoehn and Yahr (1967), reporting on a series of 802 patients, found 'mild to moderate organic mental syndrome characterized by recent memory defects and some impairment of judgement and insight' in $14 \%$ of cases. Riklan et al. (1956) compared the 50 highest and lowest in age, duration of illness, ANS impairment, rigidity and impairment of voluntary movement, from a series of 220 patients. They reported that duration of illness failed to differentiate the high and low groups on tests of cognitive function; symptom categories-notably voluntary movement impairment-were related to 'pervasive psychological deficits' including 'diminishing personality resources', and age was related to deficits normally incident to the ageing process. This last finding highlights one of the difficulties of drawing conclusions about cognitive impairment in Parkinsonism: it is largely a disease of late age when dementia-like changes may be expected in a certain proportion of the population, irrespective of the presence or absence of the disease. Later attempts to estimate the effects of age by using age-matched control groups (Horne, 1971; Marsh et al., 1971) all report some signs of cognitive and perceptual impairment in Parkinsonism, but not of the true dementia type. Results do not suggest that there is a type of impairment specific to the disease, either. Such findings as slight deficits in a variety of perceptual and cognitive tasks in patients 'otherwise intellectually intact and well orientated' are reported by Marsh et al. (1971). They do, however, point out that it is unclear whether anti-Parkinsonism drugs, depression, Parkinson's disease, or a combination of the three, are responsible for the mild cognitive impairment found. Some of the results of tests with a significant motor component, such as sentence repetition and paragraph reading time, improved after L-dopa therapy as motor control improved.

Horne (1971) postulates a 'basal ganglia cognitive deficit' to explain reaction-time anomalies and lower Standard Progressive Matrices scores in Parkinsonism patients, when there was no difference in Mill Hill Vocabulary Scale scores between the same patients and controls. It can be argued that, again, dyskinesia and fatiguability could account for these findings.

Another commonly reported mental disturbance in Parkinsonism has been investigated by Warburton (1967) and Marsh et al. (1971). The 
latter study found that Parkinsonism patients scored higher on the D.30 (depression) scale of the Minnesota Multiphasic Personality Inventory than controls, and that this continued to be true after treatment with L-dopa, when the handicapping neurological symptoms had often remitted to a large extent. This is in keeping with the comments of Mjönes that in Parkinsonism the depression often reported may be out of all proportion to the neurological deficit. Warburton (1967) suggests that depression arises in vulnerable personalities (who in his study appear to be predominantly women) because the disease is a continuing source of stress. He also reports that depression bears no relation to severity of illness, but, in fact, in his sample the women as a group tended to be more severely disabled than the men, so that the conclusions about relationships between sex and depression (or indeed severity of illness and depression) are questionable.

The present study was designed to investigate the two most commonly reported psychological disturbances in people with Parkinsonismnamely, dementia and depression.

\section{METHODS}

It was hypothesized that if Warburton's broad findings and Marsh et al.'s findings were duplicated, and if it were found that depressive symptoms occurred in association with Parkinsonism in a significant number of cases, this could well constitute a reaction to a chronic, disabling condition, which inevitably involved living at a less efficient level than hitherto, and which might not get seriously worse but had little prospect of getting better. With this in mind, the study was planned to include not only people with Parkinsonism, and healthy people from the same age group, but another group of people who also had to face an unremitting disability with wideranging implications for their mode of life. Apart from this common factor, and being from the same age-group and socioeconomic background as the Parkinsonism sufferers, this group was to have a condition with no known cerebral involvement, and no known defect of biochemistry. This was in order to restrict overlapping variables to those under consideration. Paraplegia was finally selected as a suitable condition for comparison. Although its mode of onset is more often traumatic than insidious, in which it is most unlike Parkinsonism, in other ways the problems faced under the two conditions are felt to be similar. Both involve being dis- abled and having to learn to live within the limits $\stackrel{\mathbb{D}}{=}$ imposed by the condition, both are readily recogniz- क able by other people as disabilities, and both are incurable. The three groups (Parkinsonism, para- 0 plegia, and control) were selected so as to be matched $\stackrel{0}{\infty}$ for age, distribution of sex, and distribution of $\stackrel{\overbrace{}}{=}$ socioeconomic status as measured by occupational background.

The Parkinsonism group comprised 21 current $\overrightarrow{\vec{F}}$ outpatients of the Wessex Neurological Centre, and three inpatients who had come in to be stabilized on new drug regimes while the study was going on. The $\overline{\bar{c}}$ criterion for inclusion was a primary diagnosis of Parkinsonism. No cases of drug-induced Parkinsonism, no proven post-encephalitic cases, and no cases is of Parkinsonism known to be secondary to arterio- $\overrightarrow{0}$ pathy were included, in order to eliminate some of the confounding variables.

Members of the paraplegic group were all interviewed at the National Centre for Spinal Injuries, Stoke Mandeville. Most members had been admitted $\omega_{y}$ to the centre for routine check-ups or to have such things as skin lesions or urinary infections treated. few were from a neighbouring hostel. No cases of 0 head injury, nobody known to be in renal failurêt and nobody taking diazepam as an antispasmodiि $\vec{c}$ were included, because of the known effect on mook. Twenty-four people, matched with the Parkinsonisio group for the variables already mentioned, were asked to participate. Two refused, and so the fingi $\overrightarrow{0}$ group comprised 22 paraplegics.

Members of the 'normal' control group were obtained from organizations connected with hospitals in Portsmouth and Southampton, and contacts with Portsmouth townspeople via the local Oxfam shop. Twenty people were interviewed from this group. They were matched with the other groups for age, sex, and social factors, and all were free from illness. To check the matching, age was included as a main effect in the data analysis. No between-group age differences were found to be significant. Sex distribution was not significantly different across groups $\left(\chi^{2}\right.$ $0.8523, \mathrm{P}=0.98-0.95$ ).

Each subject was interviewed individually, and testing was completed in a single session.

Two questions were posed, which the study was planned to answer:

1. Is there a general or specific cognitive deficit associated with Parkinsonism which is independent of the age of the sufferer, and if so, is it also independent of the duration and severity of his illness?

2. Is there a depressive factor in Parkinsonism, $N$ which is specific to the illness rather than to the dis- N ability associated with it, or the age or sex of the sufferer?

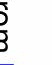


The following variables were selected for study:

1. Age at interview.

2. Duration of illness or disability (Parkinsonism and paraplegia groups only).

3. Severity of handicap caused by the illness, on a 5 -point scale from 'mild disability with full independence, and able to work' to 'heavily dependent on others including needing help with feeding, bathing, toilet'.

4. Occupation (or previous occupation if retired or a housewife). This was included to check that the three groups came from broadly comparable socioeconomic backgrounds, but not included in the data analysis.

5. Standard Progressive Matrices raw score (Raven, 1958).

6. Mill Hill synonyms raw score (Raven, 1958). Thus, straight comparisons on separate measures of verbal/educational and kinaesthetic/motor factors of intelligence were made across groups, homogeneous for age and distribution of sex and socioeconomic background, so that differences due to illness variables alone could be seen.

7. Williams's test of delayed (visual) recall, form B (Williams, 1968) administered and scored according to instructions given by the author, with a sevenminute delay.

8. Digit Span subtest of the Wechsler Adult Intelligence Scale (Wechsler, 1955) administered according to instructions from the manual. As with the Matrices and Mill Hill Scales, unconverted scores were used as age was a main effect in the data analysis.

9. Names-learning test. This test of immediate recall of 12 items is described by Irving et al. (1970).

10. The D.30 scale (Dempsey, 1964) consisting of 30 items from the Depression Scale of the Minnesota Multiphasic Personality Inventory, selected on the basis of consistent relationship to the major factor underlying the original 60 items, so as to give improved within-group distinctions.

Current medication in the Parkinsonism group was also noted.

\section{RESULTS}

The data were initially subjected to an analysis of variance (ANOVA programme, Mulhall, 1969). Results are summarized in Table 1. No between-age $F$ ratios were significant, therefore they are not included in the Table.

The broad conclusion drawn from this initial analysis was that scores on the Progressive Matrices D.30 scale, Names learning, and Williams's test were significantly different across
TABLE 1

ANALYSIS OF VARIANCE RESULTS

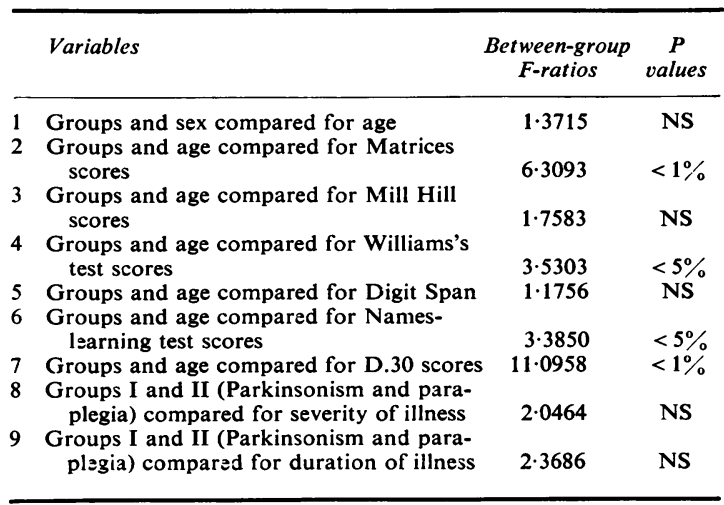

TABLE 2

SCHEFFE'S METHOD OF CONTRASTS; PROBABILITY VALUES

\begin{tabular}{lcccc}
\hline & \multicolumn{4}{c}{ Test scores } \\
\cline { 2 - 5 } Groups & Matrices & $D .30$ & Williams's & $\begin{array}{c}\text { Names- } \\
\text { learning }\end{array}$ \\
\hline $\begin{array}{c}\text { Parkinsonism } \\
v \text { control }\end{array}$ & $5 \%$ & $5 \%$ & NS & $5 \%$ \\
$\begin{array}{c}\text { Parkinsonism } \\
v \text { paraplegia }\end{array}$ & NS & NS & NS & NS \\
$\begin{array}{c}\text { Paraplegia } \\
v \text { control }\end{array}$ & NS & NS & NS & NS \\
\hline
\end{tabular}

the three groups. Scheffe's method of contrasts (Guenther, 1965) was applied to all possible pairs of groups for each significant variable, so as to determine the source of variation more precisely. Results for a 5\% probability level are shown in Table 2.

The only clear difference shown by this procedure is that between the Parkinsonism and control groups on three of the tests. When the control group was contrasted with both of the others on Williams's test, using the same method, it was found that the test differentiated the control group from both disabled groups, but did not distinguish between the latter. These findings raised the question of the influence of the severity and duration of the handicap on the test results. In the analysis of variance, both these variables had produced $F$ ratios not significant at the 0.05 level. However, it was felt to be 
at least a possibility that, although when taken separately they were not affecting results, when looked at in combination the effect they produced could not be equated across the two groups. A chi-square test, using a $2 \times 4$ contingency table (two disabled groups by four conditions; high severity, high duration; high severity, low duration; low severity, low duration; low severity, high duration) was carried out to check this possibility, with the high-low cut off points drawn as close to the medians as possible. The result of chi-square significant at the 0.05 level was taken to confirm the uneven distribution of the variables with respect to the two groups. Since these variables had not been controlled experimentally, a statistical method of control was needed to allow for their effects on the data. Accordingly, an analysis of covariance (Kirk, 1968) was carried out to remove the effects of these two contaminating variables. Results are summarized in Table 3.

TABLE 3

ANALYSIS OF COVARIANCE RESULTS

\begin{tabular}{llcc}
\hline $\begin{array}{c}\text { Covariates (severity and duration of } \\
\text { illness controlled) }\end{array}$ & F-ratios & $P$ values \\
\hline 1 & $\begin{array}{c}\text { Groups I and II compared for Matrices } \\
\text { scores }\end{array}$ & 7.75 & $<1 \%$ \\
2 & $\begin{array}{c}\text { Groups I and II compared for Mill Hill } \\
\text { scores }\end{array}$ & 1.00 & $\mathrm{NS}$ \\
$3 \quad \begin{array}{c}\text { Groups I and II compared for Williams's } \\
\text { test scores }\end{array}$ & $<1$ & $\mathrm{NS}$ \\
$4 \quad$ Groups I and II compared for Digit Span & $<1$ & $\mathrm{NS}$ \\
5 Groups I and II compared for Names- & $<1$ & $\mathrm{NS}$ \\
6 learning test scores & 10.12 & $<1 \%$ \\
\hline
\end{tabular}

It can be seen from these results that discrimination between the Parkinsonism group and the others, on the Progressive Matrices and D.30 scale, is improved when severity and duration of handicap are controlled for. On these two tests, then, there is apparently an adverse factor in operation, which is related to the disease itself, and not to any other variables. All other tests fail to discriminate the Parkinsonism group specifically from the others, whether or not severity and duration of handicap are controlled for.

\section{DISCUSSION}

It seems from the above results that depressive $\underset{0}{\stackrel{C}{c}}$ symptoms as measured by the $\mathrm{D} .30$ scale are $D$ significantly related to the presence of Parkinsonism. and that this relationship is independent of $\frac{\mathrm{O}}{\mathrm{g}}$ the effects of the severity of handicap associated with the illness, or its length of duration, or the age or sex of the sufferer. In view of a suggestion of Warburton (1967) that sex is related to depression in Parkinsonism, this was also investi- $\frac{\bar{O}}{\bar{D}}$ gated. D.30 scores for male and female Parkin- $\frac{\infty}{\widehat{D}}$ sonism patients were compared and found not $\stackrel{\mathbb{\Omega}}{\circ}$ to be significantly different $\left(\chi^{2} 0 \cdot 14, \mathrm{P}>0.9\right)$. क This result is broadly in agreement with Mjöne's $\vec{O}$ comments, and Marsh et al.'s findings that a $\overrightarrow{\vec{\omega}}$ group of Parkinsonism patients tested on the MMPI scored 'in the moderate to severe range for depression' before and after treatment with? L-dopa when neurological symptoms had often remitted to a large extent.

That there was no difference between the three groups on the Mill Hill vocabulary anf Digit Span tests, suggests that the group meno bers were homogeneously distributed with respect to verbal educational level, so that the lower Progressive Matrices scores from the Parkinsonism group may be considered to be 'real' difference rather than the result of sampling error. It is paralleled by results from a recent study by Horne (1971) on delayed response tasks, in which the Matrices and Mill Hill tests were administered to controls and Parkinsonism patients before the experimental trials. Horne reports that there was no difference between groups on 'Mill Hill IQs, but on P.M. (Matrices) the control group had significantly음 higher IQs'. Horne suggests that this may be evidence of perceptual impairment due to basal ganglia damage. However, applying the principle $\frac{0}{5}$ of parsimony to Horne's results and those found 3 in the present study, it should be pointed out $\delta$ that the Matrices test requires sustained effort of concentration over a period of time, and that 의 fatiguability is a known factor in Parkinsonism $D$ (Calne, 1970, quoting Schwab et al., 1959). It seems likely that muscular fatiguability with its $N$ accompanying subjective feelings of restlessness $\mathrm{N}$ and limb discomfort has an adverse effect on performance of tasks requiring sustained con- $\omega$ centration like the Matrices. Effects of this can- 
not be estimated from the present study because the Matrices was administered in a standard way so that the effects of increasing difficulty cloud the issue; it is put forward as a tentative hypothesis.

Horne puts forward other evidence to suggest that a 'basal ganglia cognitive deficit' can be elicited by asking the subject to perform a sensorimotor interaction-for example, visual/ vocal; an oral response to a visual stimulusand in his study shows that under delayedresponse conditions, controls improve on reaction time measured under non-delay conditions, but Parkinsonism subjects continue to respond at the same rate. It is felt that a conclusion of cognitive deficit may not validly be drawn from this result for the following reasons:

1. Hypokinesia, which involves difficulty in initiating motor response as well as poverty of movement, and which is related to muscular fatiguability, is a major symptom of Parkinsonism and might well be exerting a significant influence on performance on such a task under conditions with extra variables such as delay of response.

2. Sensorimotor interactions are involved in virtually all psychological tests, and although timed tests might penalize subjects with Parkinsonism for the reasons just given, there is as yet no evidence of deficit in any but the motor component of such tasks.

\section{CONCLUSIONS}

It is concluded from the results of the present study that Parkinsonism and depression as measured by the D.30 are significantly related, irrespective of the age and sex of the patient, and of the severity and duration of the condition.

It has also been demonstrated that scores on the Matrices test are lower in people with Parkinsonism than in two other groups of people of comparable age, sex, and verbal intelligence as measured by the Mill Hill Synonym scale.

It is suggested that fatigue is directly related to rigidity and hypokinesia, which are prominent features of the disease.
I should like to thank Mr. J. Brice, Mr. J. Garfield, Dr. G. S. Graveson, Dr. P. K. Robinson, and Dr. L. S. Illis (Wessex Neurological Centre) and Dr. J. Walsh and Dr. H. Frankel (Stoke Mandeville Hospital) for their kind interest and permission to see their patients; Miss A. M. Silver (Psychology Department, St. James's Hospital, Portsmouth) and Mr. J. R. Compton (Psychology Department, Knowle Hospital, Fareham) for reading the manuscipt and for their helpful comments; Dr. D. Marcer (Psychology Department, Southampton University) and Mr. D. Mulhall (Psychology Department, Wessex Unit for Children and Parents) for statistical guidance, and Miss A. Poole (Wessex Neurological Centre) for typing the manuscript.

\section{REFERENCES}

Calne, D. B. (1970). Parkinsonism. Physiology, Pharmacology and Treatment. Arnold: London.

Dempsey, P. (1964). A unidimensional depression scale for the MMPI. Journal of Consulting Psychology, 28, 364-370.

Guenther, W. C. (1965). Concepts of Statistical Inference. McGraw-Hill: New York.

Hoehn, M. M., and Yahr, M. D. (1967). Parkinsonism: onset, progression, and mortality. Neurology (Minneap.), 17, 427-442.

Horne, D. J. de L. (1971). Performance on delayed response tasks by patients with Parkinsonism. Journal of Neurology, Neurosurgery, and Psychiatry, 34, 192-194.

Irving, G., Robinson, R. A., and McAdam, W. (1970). The validity of some cognitive tests in the diagnosis of dementia. British Journal of Psychiatry, 117, 149-156.

Kirk, R. E. (1968). Experimental Design: Procedures for the Behavioral Sciences. Brooks/Cole: Belmont, Calif.

Lewy, F. H. (1923). Die Lehre vom Tonus und der Bewegung. Springer: Berlin.

Marsh, G. G., Markham, C. M., and Ansel, R. (1971). Levodopa's awakening effect on patients with Parkinsonism. Journal of Neurology, Neurosurgery, and Psychiatry, 34, 209-218.

Mjönes, H. (1949). Paralysis agitans. Acta Psychiatrica et Neurologica. Suppl. 54.

Mulhall, D. (1969). ANOVA. A program to perform the analysis of variance. (Unpublished.)

Parkinson, J. (1817). An Essay on the Shaking Palsy. Sherwood, Neely, and Jones: London.

Raven, J. C. (1958). Guide to using the Mill Hill Vocabulary Scale with the Progressive Matrices Scales. Lewis: London.

Riklan, M., Weiner, H., and Diller, L. (1959). Somatopsychologic studies in Parkinson's disease. 1. Journal of Nervous and Mental Disease, 129, 263-272.

Warburton, J. W. (1967). Depressive symptoms in Parkinsonism patients referred for thalamotomy. Journal of Neuro$\log y$, Neurosurgery, and Psychiatry, 30, 368-370.

Wechsler, D. (1955). Manual for the Wechsler Adult Intelligence Scale. Psychological Corporation: New York.

Williams, M. (1968). The measurement of memory in clinical practice. British Society of Clinical Psychology, 7, 19-34. 